\title{
Preliminary evaluation of selected Prunus spinosa and $P$. insititia genotypes for their nutraceutical properties
}

\author{
Papp, N. ${ }^{1,2}$, Szőke, F. ${ }^{2}$, Szabó, Z. ${ }^{2}$, Nyéki, J. ${ }^{2}$, Stefanovits-Bányai, É. ${ }^{1} \&$ Hegedús, A. ${ }^{3}$ \\ ${ }^{1}$ Corvinus University of Budapest, Faculty of Food Science, Department of Applied Chemistry, \\ 1118 Budapest, Villányi út 29., Hungary \\ ${ }^{2}$ University of Debrecen, Centre of Agricultural Sciences, H-4032, Debrecen, Hungary \\ ${ }^{3}$ Corvinus University of Budapest, Faculty of Horticultural Science, Department of Genetics and Plant Breeding, \\ 1118 Budapest, Villányi út 29., Hungary; E-mail: hegedus.attila@uni-corvinus.hu
}

\begin{abstract}
Summary: Fruits of nine Prunus spinosa and P. insititia selections were compared in their ferric reducing antioxidant power and total phenolic content. The antioxidant capacity and total phenolic content ranged between 6.36 and $29.26 \mathrm{mmol}$ AA/L, and 5.04 and $29.71 \mathrm{mmol}$ GA/L, respectively. These ranges cover an almost 5-times variation among the tested genotypes. The Pearson's coefficient was very high (0.92) indicating a major contribution of polyphenolics to the antioxidant capacity of the tested Prunus fruits. Conserving resulted in an approximate $20 \%$ loss of antioxidant power and slightly increased phenolic contents. Our results led us to the conclusion that fruit of Prunus spinosa and $P$. insititia might be considered as rich sources of antioxidants. In addition, procession with heat treatment caused only a slight decrease in the antioxidant capacity without loss in the total polyphenolic content.
\end{abstract}

Key words: antioxidant, blackthorn, plums, Prunus insititia, Prunus spinosa, total phenolics

\section{Introduction}

Epidemiological studies suggest that increased fruit consumption decreases the risk of several degenerative diseases including atherosclerosis, heart and brain disorders or different types of cancer (Block and others 1992; Dauchet and Dallongeville 2008). Medical studies have revealed that health-promoting effects of fruits are due to the additive and synergistic combinations in a complex mixture of several thousand phytochemicals, many of which possess strong antioxidant capacity including ascorbic acid, flavonoids, carotenoids etc. ( Liu, 2003).

Besides the main stone fruit crops, additional minor species are characterized by growing importance, mainly associated with their expected health-promoting value (Celik et al., 2011; Kumarasamy et al., 2004). Among others (e.g. strawberry-tree berries and dog rose hips), blackthorn fruits were characterized for their chemical composition and biological properties were evaluated (Barros et al., 2010). The analysed fruits contained very useful bioactive phytochemicals such as phenolics, vitamins (ascorbic acid and tocopherols) and carotenoids. All the samples proved to have antioxidant activity. The combination of bioactive compounds and rich nutritional composition (high contents in carbohydrates, low contents in fat with the precious contribution of polyunsaturated fatty acids, precursors of omega- 3 and omega- 6 fatty acids) of the studied fruits make them a very perspective food.
Vitamin A (390 g), C (7,70 mg), E (2,75 mg), B1 (0,31 $\mathrm{mg}), \mathrm{B} 2(0,80 \mathrm{mg}), \mathrm{B} 6(0,84 \mathrm{mg})$, niacin $(2,10 \mathrm{mg})$, folate $(24,75 \mathrm{~g})$ and some organic acid concentrations including malic $(158 \mathrm{mg})$, lactic $(126 \mathrm{mg})$, citric $(44 \mathrm{mg})$, fumaric $(1,64)$ and quinic acids (non-detectable) in 100 gram dry weight were detected in the fruits of Prunus spinosa subsp. dasyphllum (Özcan, 2008).

Dragovic-Uzelac et al. (2007) compared the total antioxidant capacity of several berry crops. The highest antioxidant capacity was determined in cornelian cherry fruits and decreased in other fruits as follow: sour cherry, blackthorn and strawberry. Among several classes of polyphenolics, blackthorn also contain anthocyanins, at least, in its fruit skin. The antiradical capacity of some anthocyanin-based fruit extracts was studied by using the 2,2-diphenyl-1-picrylhydrazyl radical (DPPH') (Espin et al., 2000). These natural colourants proved to be a valuable combined source of colour and radical scavenging activity for food material.

Among plums, $P$. domestica is the most intensively studied species. In one of the most comprehensive studies, the total antioxidant capacity ranged from 105 to $424 \mathrm{mg}$ ascorbic acid equivalents $/ 100 \mathrm{~g}$ fresh weight (FW) while the total phenolic content was $86-413 \mathrm{mg}$ gallic acid equivalents $/ 100 \mathrm{~g}$ FW among 20 genotypes (Rupashinge et al., 2006). A direct correlation between skin colour intensity and total phenolic content was also observed. This study demonstrated that there is adequate variation in total phenolic compounds 
and antioxidants within European plums and hence there is potential for improvement towards enhancing these healthpromoting phytochemicals in this fruit.

The present study was carried out to characterize the antioxidant power of two less known Prunus species and find out whether they can be used as a processed fruit with some health-benefits.

\section{Materials and methods}

\section{Cultivars tested}

Altogether, nine blackthorn (Prunus spinosa L.) and Prunus insititia selections were used for the analyses, all provided by Ferenc Szőke private breeder. All were cultivated at the same orchard (Lövőpetri, NorthEastern Hungary). Fruits were collected during the season of 2009 and processed into conserves based on a standard protocol.

\section{Fruit sample preparation}

For antioxidant assays, $100 \mathrm{~g}$ fruit were homogenized (peel and flesh together) and centrifuged with a Hettich Zentrifugen (Mikro 22 R; Tuttlingen, Germany) device $\left(4{ }^{\circ} \mathrm{C}, 35 \mathrm{~min}\right.$, $18750 \mathrm{~g}$ ), after which supernatants were used for most of the redox assays (exceptions are indicated). Samples for further analyses were kept at $-80^{\circ} \mathrm{C}$ until use.

\section{Antioxidant and total phenolic assays}

Antioxidant capacity was determined by the FRAP method (Benzie, \& Strain, 1996) and expressed as mmol ascorbic acid (AA)/L fruit juice or mol AA/100 $\mathrm{g}$ fresh weight. Total phenolic content (TPC) was measured using Folin-Ciocalteu's reagent according to the method of Singleton \& Rossi (1965). The content of soluble phenols was calculated from a standard curve based on gallic acid concentration.

\section{Statistical analysis}

Data presented for each cultivar represent the mean values determined from three independent homogenates. Correlation coefficients of redox parameters were determined by the coefficient of Pearson. One-way analysis of variance (ANOVA) was carried out in Microsoft Excel Lövőpetri, Hungary. Lövőpetri, Hungary.
2003. Differences at $P £ 0.05$ were considered statistically significant.

\section{Results and discussion}

The antioxidant capacity measured by the ferric reducing ability of samples ranged between 6.36 and $29.26 \mathrm{mmol}$ AA/L, with an average value of $13.47 \mathrm{mmol} \mathrm{AA} / \mathrm{L}$. This range represents an almost 5-times variation among the tested genotypes. The lowest FRAP values were measured in fruit extracts of the L1 genotype, while the highest values were obtained for genotype S2 (Figure 1).

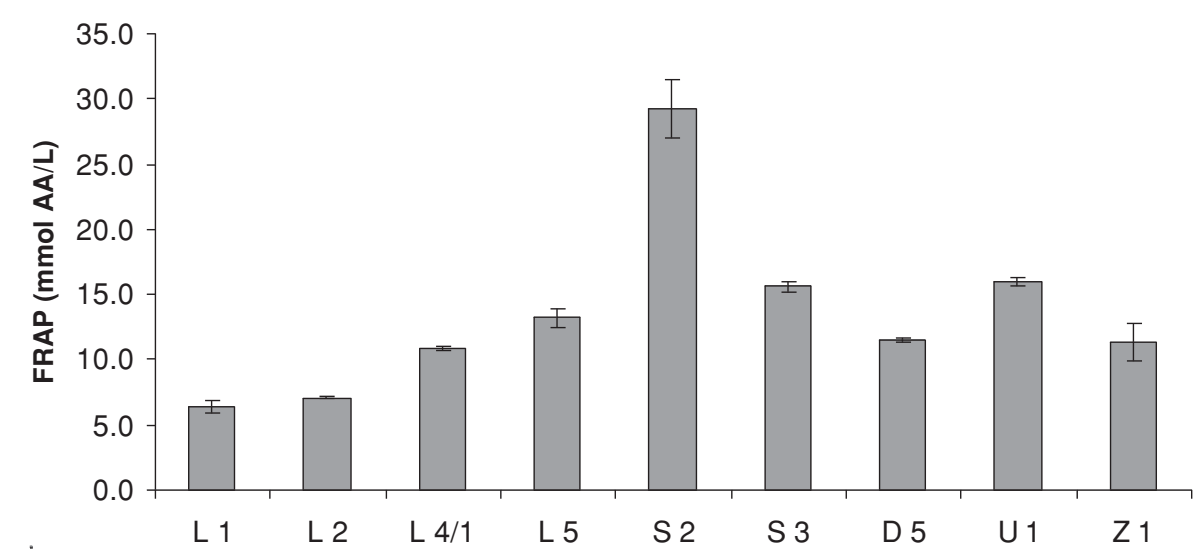

Figure 1. Antioxidant capacity in fruits of Prunus spinosa and P. insititia selections, collected in 2009,

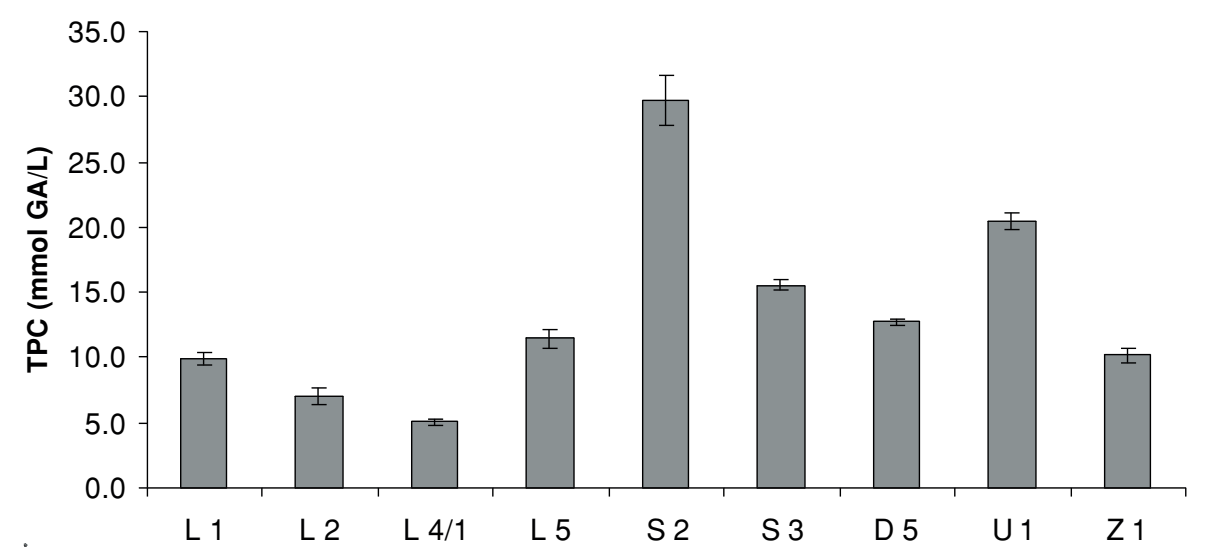

Figure 2. Total phenolics content in fruits of Prunus spinosa and P. insititia selections, collected in 2009,

The total phenolic contents in samples ranged between 5.04 and $29.71 \mathrm{mmol} \mathrm{GA} / \mathrm{L}$, with an average value of 13.57 mmol GA/L. This range also covers an almost 5-times variation among the tested genotypes. The lowest TPC values were measured in fruit extracts of the L4/1 genotype, while the highest values occurred again for the genotype S2 (Figure 2).

The Pearson's coefficient was very high (0.92) indicating both a major contribution of polyphenolics to the antioxidant capacity of $P$. spinosa and $P$. insititia fruit and similar chemistry behind the two antioxidant assays (Huang et al., 2005). Strong correlations were detected for many stone fruit 
crops like apricot, sour cherry, several types of berries (Cevallos-Casals et al., 2006; Hegedüs et al., 2008; 2010; Papp et al., 2010; Yildiz et al., 2010). Similarly, the two parameters had a strong correlation of $r^{2}=0.96$ also in European plum (Rupashinge et al., 2006).
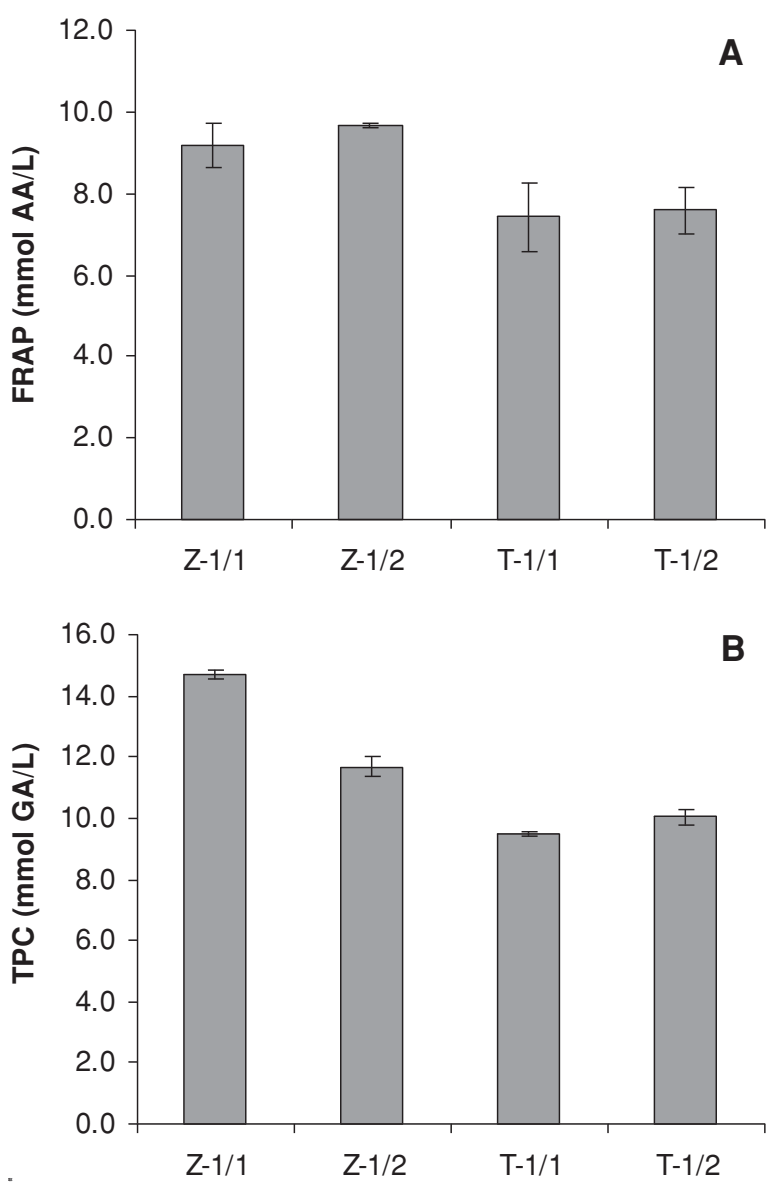

Figure 3. Antioxidant capacity (A) and total phenolics content (B) in conserved fruits of blackthorn selections, collected in 2009, Lövőpetri, Hungary.

The fruits of some genotypes were processed to find out how much of the antioxidant capacity and total phenolic content will be lost during standard procedure of conserve making. The conserved fruits of the genotype Z1/1 had a FRAP value of $9.20 \mathrm{mmol} \mathrm{AA} / \mathrm{L}$ compared with the value of $11.38 \mathrm{mmol} \mathrm{AA} / \mathrm{L}$ in the fresh fruit, indicating an approximately $20 \%$ decrease in the antioxidant capacity. This might be associated with the decomposition of ascorbic acid and other heat labile compounds and dissolution of some antioxidants from the softened fruit tissues. However, dissolution of the phenolic compounds is not likely as the total phenolics content of conserved fruits were even higher than that of fresh fruits in case of the $\mathrm{Z1}$ genotype.

Our results led us to the conclusion that fruit of Prunus spinosa and $P$. insititia might be considered as rich sources of antioxidants. In addition, procession with heat treatment caused only a slight decrease in the antioxidant capacity without loss in the total polyphenolic content.
Acknowledgements. This work was co-financed by NFÜ TECH_08-A3/2-2008-0373 and the OTKA K84290 grants. Attila Hegedüs is grateful for receiving a János Bolyai Scholarship, Hungarian Academy of Sciences and Éva Stefanovits-Bányai for the award Excellence in Science, Corvinus University of Budapest.

\section{References}

Barros, L., Carvalho, A.M., Morais, J.S. \& Ferreira I.C.F.R. (2010): Strawberry-tree, blackthorn and rose fruits: Detailed characterisation in nutrients and phytochemicals with antioxidant properties. Food Chem., 120: 247-254.

Benzie, I.I.F. \& Strain, J.J. (1996): The ferric reducing ability of plasma (FRAP) as a measuring of "antioxidant power": The FRAP assay. Ann. Biochem., 239: 70-76.

Block, G., Patterson, B. \& Subar, A. (1992): Fruit, vegetables, and cancer prevention: A review of the epidemiological evidence. Nutr. Cancer, 18:1-29.

Celik, F., Ercisli, S., Yilmaz, S.O. \& Hegedüs, A. (2011): Estimation of certain physical and chemical fruit characteristics of various cherry laurel (Laurocerasus officinalis Roem.) genotypes. HortScience, 46(6): 924-927.

Cevallos-Casals, B.A., Byrne, D., Okie, W.R. \& CisnerosZevallos, L. (2006): Selecting new peach and plum genotypes rich in phenolic compounds and enhanced functional properties. Food Chem., 96: 273-280.

Dragovic-Uzelac, V., Levaj, B., Bursac, D., Pedisic, S., Radojcic, I. \& Bisko, A. (2007): Total phenolics and antioxidant capacity assays of selected fruits. Agriculturae Conspectus Scientificus, 72: 279-284.

Espín, J.C., Soler-Rivas, C., Wichers, H.J. \& García-Viguera, C. (2000): Anthocyanin-based natural colorants: A new source of antiradical activity for foodstuff. J. Agric. Food Chem., 48: $1588-1592$.

Hegedüs, A., Balogh, E., Engel, R., Sipos, B.Z., Papp, J., Blázo vics, A. \& Stefanovits-Bányai, É. (2008): Comparative nutrient element and antioxidant characterization of berry fruit species and cultivars grown in Hungary. HortScience, 43:1711-1715.

Hegedús, A., Engel, R., Abrankó, L., Balogh, E., Blázovics, A., Hermán, R., Halász, J., Ercisli, S., Pedryc, A. \& StefanovitsBányai, É. (2010): Antioxidant and antiradical capacities in apricot (Prunus armeniaca L.) fruits: variations from genotypes, years and analytical methods. J. Food Sci., 75(9): 722-730.

Hegedűs, A., Pfeiffer, P., Papp, N., Abrankó, L., Pedryc, A. \& Stefanovits-Bányai, É. (2011): Accumulation of antioxidants in apricot fruit through ripening: characterization of a genotype with enhanced functional properties. Biol. Res., 44: 201-206.

Huang, D.J., Ou, B.X. \& Prior, R.L. (2005): The chemistry behind antioxidant capacity assays. J. Agric. Food Chem., 53: $1841-1856$.

Kumarasamy, Y., Cox, P.J., Jaspars, M., Nahar, L. \& Sarker, S.D. (2004): Comparative studies on biological activities of Prunus padus and $P$. spinosa. Fitoterapia, 75: 77-80.

Liu, R.H. (2003): Health benefits of fruit and vegetables are from additive and synergistic combinations of phytochemicals. Amer. J. Clin. Nutr., 78: 517-520. 
Özcan, T. (2008): Some vitamin and organic acid contents in the fruits of Prunus spinosa L. subsp. dasyphylla (Schur) Domin from Europe-in-Turkey. IUFS J. Biol., 67: 105-117.

Papp, N., Szilvássy, B., Abrankó, L., Szabó, T., Pfeiffer, P., Szabó, Z., Nyéki, J., Ercisli, S., Stefanovits-Bányai, É. \& Hegedüs, A. (2010): Main quality attributes and antioxidants in Hungarian sour cherries: identification of genotypes with enhanced functional properties. Int. J. Food Sci. Tech., 45: 395-402.

Pfeiffer, P. \& Hegedús, A. (2011): Review of the molecular genetics of flavonoid biosynthesis in fruits. Acta Aliment., 40(Suppl.): 150-163.
Rupasinghe, H.P.V., Jayasankar, S. \& Lay, W. (2006): Variation in total phenolics and antioxidant capacity among European plum genotypes. Sci. Hort., 108: 243-246.

Singleton, V.L. \& Rossi, J.A. (1965): Colorimetry of total phenolics with phosphomolybdic phosphotungstic acid ,reagents". Am. J. Enol. Vitic., 16: 144-158.

Yildiz, H., Sengul, M., Celik, F., Hegedus, A., Ercisli, S., Tosun, M. (2010): Some phytochemical and antioxidant characteristics of wild and cultivated blackberry fruits (Rubus caucesicus). J. Food Agric. Environ., 8: 156-159. 